\title{
Suppression of Cucumber Powdery Mildew by Supplemental UV-B Radiation in Greenhouses Can be Augmented or Reduced by Background Radiation Quality
}

\author{
A. Suthaparan, Department of Plant Sciences, Norwegian University of Life Sciences, 1432 Ås, Norway; A. Stensvand, Norwegian \\ Institute for Agricultural and Environmental Research, Høgskoleveien 7, 1432 Ås, Norway; K. A. Solhaug, Department of Ecology and \\ Natural Resource Management, Norwegian University of Life Sciences, 1432 Ås, Norway; S. Torre, K. H. Telfer, A. K. Ruud, and \\ L. M. Mortensen, Department of Plant Sciences, Norwegian University of Life Sciences; D. M. Gadoury and R. C. Seem, Department \\ of Plant Pathology and Plant-Microbe Biology, Cornell University, New York State Agricultural Experiment Station, Geneva, NY \\ 14456; and H. R. Gislerød, Department of Plant Sciences, Norwegian University of Life Sciences
}

\begin{abstract}
Suthaparan, A., Stensvand, A., Solhaug, K. A., Torre, S., Telfer, K. H., Ruud, A. K., Mortensen, L. M., Gadoury, D. M., Seem, R. C., and Gislerød, H. R. 2014. Suppression of cucumber powdery mildew by supplemental UV-B radiation in greenhouses can be augmented or reduced by background radiation quality. Plant Dis. 98:1349-1357.

This study demonstrates that the spectral quality of radiation sources applied with ultraviolet-B (UV-B; background radiation) affects the suppression of cucumber powdery mildew (Podosphaera xanthii) by UV-B. Suppression provided by daily UV-B exposure of $1 \mathrm{~W} / \mathrm{m}^{2}$ for 10 min was greatest in the presence of red light or by a complete lack of background light, and powdery mildew suppression was least in the presence of ultraviolet-A (UV-A) or blue radiation compared with plants exposed only to $16 \mathrm{~h}$ of daily natural light supplemented with high-pressure sodium lamps that supply broad-spectrum radiation with peaks in the yellow-orange region. Exposure of powdery mildew-inoculated plants to supplemental red light without UV-B, beginning at the end of the daylight period, also reduced disease severity; however, supplemental blue light applied in the same fashion had no effect. Daily application of UV-B at $1 \mathrm{~W} / \mathrm{m}^{2}$ beginning on the day of inoculation significantly reduced the severity of powdery mildew to $15 \%$ compared with $100 \%$ severity on control plants. Maximum suppression of

powdery mildew was observed following 15 min of exposure to UV-B (1.1\% severity compared with $100 \%$ severity on control plants) but exposure time had to be limited to 5 to $10 \mathrm{~min}$ to reduce phytotoxicity. There was no additional disease suppression when plants were exposed to UV-B beginning 2 days prior to inoculation compared with plants exposed to UV-B beginning on the day of inoculation. UV-B inhibited germination, infection, colony expansion, and sporulation of $P$. xanthii. The results suggest that efficacy of UV-B treatments, alone or in combination with red light, against $P$. xanthii can be enhanced by exposure of inoculated plants to these wavelengths of radiation during the night, thereby circumventing the counteracting effects of blue light and UV-A radiation. The effect of UV-B on powdery mildew seemed to be directly upon the pathogen, rather than induced resistance of the host. Night exposure of plants to 5 to $10 \mathrm{~min}$ of UV-B at $1 \mathrm{~W} / \mathrm{m}^{2}$ and inexpensive, spectral-specific, light-emitting diodes may provide additional tools to suppress powdery mildews of diverse greenhouse crops.
\end{abstract}

Powdery mildew can be a devastating disease wherever cucumber (Cucumis sativus) and other cucurbit hosts are grown, and can be caused by three different fungi: Podosphaera xanthii, Golovinomyces cichoracearum, and Leveillula taurica (4). P. xanthii is the most widespread of the three and is consistently problematic, particularly in greenhouse cucumber production (38). Despite the development and use of cucumber cultivars displaying a range of resistance to this pathogen group, and intensive use of fungicides in most greenhouse cucurbit production systems, powdery mildews continue to present significant challenges to sustainable production (52). The inherent genetic variability and high reproductive potential of powdery mildews creates both a system that requires intensive fungicide use and a propensity for development of resistance within the pathogen population $(28,31,51)$. Many powdery mildew fungi, particularly $P$. xanthii, have developed resistance to at least six fungicide groups: benzimidazoles, demethylation inhibitors, morpholines, hydroxypyrimidines, phosphorothiolates, and quinine outside inhibitors $(20,32,33)$.

Corresponding author: A. Suthaparan,

E-mail: aruppillai.suthaparan@nmbu.no

* The $e$-Xtra logo stands for "electronic extra" and indicates that four supplementary figures are available online and that Figures 5 and 7 appear in color online.

Accepted for publication 11 April 2014.

http://dx.doi.org/10.1094/PDIS-03-13-0222-RE

(C) 2014 The American Phytopathological Society
Light is a predominant factor in control of growth, development, and stress responses of plants. In addition to being a source of energy, light is an important regulator of the interaction between plants and parasites $(22,24)$. Ultraviolet (UV) radiation is a shortwavelength part of electromagnetic radiation which can be divided further into UV-A, UV-B, UV-C, and vacuum UV radiation (3). Despite numerous studies showing the effects of light and UV radiation on plant-pathogen (including powdery mildew fungi) interactions under controlled laboratory conditions $(17,37,40,42$, 49,50), few studies have focused on applying this knowledge for disease management $(2,15,23)$. Reduced powdery mildew severity with increased UV-B dose was reported in grapevines when plant canopies were manipulated to increase light penetration (2). Exposure of grapevines to UV-C radiation also reduced severity of powdery mildew (15) but caused phytotoxicity at doses only slightly greater than those required to suppress disease (D. M. Gadoury, unpublished data). Significant reduction in powdery mildew severity also has been reported in strawberry plants exposed to supplemental UV-B radiation (23). In contrast, powdery mildew on oak (Quercus robur) saplings caused by Microsphaera alphitoides was more abundant under supplemental UV radiation that supplied both UV-A and UV-B compared with ambient radiation only (36). Recent studies reported methods by which the spectral quality, intensity, and timing of light can be manipulated to suppress powdery mildew of rose, and these studies were expanded to include other powdery mildews and UV-B radiation $(45,46,48)$. Daily exposure of inoculated plants to UV-B radiation for $5 \mathrm{~min}$ at $1.2 \mathrm{~W} / \mathrm{m}^{2}$ during the night significantly reduced powdery mildew severity on pot roses without causing phytotoxicity (45).

Even though numerous studies have examined the impact of spectral qualities of light on plant pathogens $(37,42,48,49)$, little is 
known of the impact of different spectral qualities supplied by various radiation sources on the efficacy of UV-B radiation for plant disease control. To optimize the efficacy of UV-B radiation for disease control, it is important to understand how various wavelengths of electromagnetic radiation act together with UV-B to affect pathogen development and disease suppression. Previous studies have indicated that these interactions can be significant. For example, solar radiation that had the lowest ratio of blue/UV radiation transmitted through polyethylene films was associated with the greatest number of Botrytis cinerea infection sites in greenhouse-grown tomato compared with tomato exposed to a greater ratio of blue/UV radiation (39). Furthermore, growth chamber experiments conducted with polyethylene films with different blue/UV radiation transmission ratios revealed a significant negative correlation between blue/UV radiation ratio and sporulation of B. cinerea (39). In this study, the following were evaluated: (i) the use of UV-B radiation to suppress cucumber powdery mildew caused by $P$. xanthii and (ii) how specific qualities of background lighting can augment or reduce the suppressive effects of UV-B on this fungus. Preliminary results of portions of this work have been reported $(44,46)$.

\section{Materials and Methods}

Plant production, inoculum production, and plant inoculation. Seeds of the powdery mildew-susceptible cucumber 'Confida' (Rijk Zwaan) were sown in 12-cm-diameter plastic pots containing a 3:1 mixture of standard growth medium (VEKSTTORV; Ullensaker Almenning) and perlite. The plants were grown in a greenhouse under supplemental lighting provided by high-pressure sodium (HPS) lamps (Lucalox LU400/XO/T/40; GE Lighting). HPS lamps augmented natural daylight to provide a day length of $18 \mathrm{~h}$ with minimum photosynthetic photon flux (400 to $700 \mathrm{~nm})$ of $200 \pm 20 \mu \mathrm{mol} / \mathrm{m}^{2} / \mathrm{s}$ at plant height (Fig. 1), as described previously (45). Temperature and relative humidity $(\mathrm{RH})$ in the greenhouse were regulated with a mean (and range) of $20^{\circ} \mathrm{C}\left(15\right.$ to $\left.32^{\circ} \mathrm{C}\right)$ and $84 \%$ (41 to $95 \%$ ), respectively. Plants were irrigated with a complete nutrient solution prepared by mixing Kristalon Indigo and YaraLiva Calcinite (1:1 [ $\mathrm{vol} / \mathrm{vol}]$ ) (Yara International ASA), for final electrical conductivity of $1.5 \mathrm{mS} / \mathrm{cm}^{2}$.

$P$. xanthii was isolated from diseased leaves of cucumber obtained from a commercial greenhouse in Lier, Norway, and was transferred sequentially to clean leaf disks cut from the second true leaves of healthy cucumber plants (Confida). Leaf disks were incubated for 7 to 9 days in petri dishes containing water agar at $20^{\circ} \mathrm{C}$ under $14 \mathrm{~h}$ of daily lighting supplied by mercury lamps, as described previously (47). At 7 days following inoculation, conidial suspensions were prepared by placing the leaf disks in distilled water containing Tween 20 (Sigma-Aldrich Chemie $\mathrm{GmbH}$ ) at 20 $\mu \mathrm{l} / \mathrm{liter}$ and shaking the leaf disks gently to remove conidia. Each suspension was adjusted to a minimum of $8 \times 10^{4}$ conidia $/ \mathrm{ml}$, and was sprayed onto healthy cucumber plants at the rate of 10 $\mathrm{ml} /$ plant, as described previously (45). Inoculated plants were kept in isolated growth chambers, and pathogen inoculum was renewed weekly, as described previously, to maintain fresh inoculum throughout the experiments (45).

Effects of daily duration of UV-B exposure and exposure timing (pre- and postinoculation exposure) on powdery mildew, plant growth, and plant physiology. A factorial experiment was conducted to examine the optimal duration and timing of UV$\mathrm{B}$ exposure: factor one was duration of daily UV-B exposure of 0 , 5,10 , or $15 \mathrm{~min}$; and factor two was the initiation of UV-B exposure, with the start of exposure to UV-B 2 days prior to inoculation, the day of inoculation, or 3 days postinoculation. At the first-trueleaf growth stage (approximately 2 weeks after sowing), 72 plants were moved to a greenhouse compartment with $16 \mathrm{~h}$ of daily growth light (GL) provided by solar radiation supplemented with HPS lamps which delivered $100 \pm 10 \mu \mathrm{mol} / \mathrm{m}^{2} / \mathrm{s}$ whenever solar irradiance fell $<200 \mathrm{~W} / \mathrm{m}^{2}$. Plants were then divided into three groups, each of which had 24 plants. While the plants in two of the groups were under $16 \mathrm{~h}$ of GL, the first group of plants was exposed to the following daily UV-B treatment to understand whether UV-B induced any resistance to powdery mildew if applied prior to inoculation: (i) $16 \mathrm{~h}$ of GL followed by darkness, (ii) $16 \mathrm{~h}$ of GL followed by night exposure to UV-B $\left(1 \mathrm{~W} / \mathrm{m}^{2}\right)$ for $5 \mathrm{~min}$, (iii) $16 \mathrm{~h}$ of GL followed by night exposure to UV-B $\left(1 \mathrm{~W} / \mathrm{m}^{2}\right)$ for $10 \mathrm{~min}$, and (iv) $16 \mathrm{~h}$ of GL followed by night exposure to UV-B $\left(1 \mathrm{~W} / \mathrm{m}^{2}\right)$ for $15 \mathrm{~min}$ (Supplementary Figure 1). To avoid interplot interference, the greenhouse compartment was partitioned using 1-mmthick white sheets of plastic. UV-B radiation was supplied by UVB fluorescent tubes (Model UVB-313EL; Q-PANEL Lab Products). Two days later, plants in all three groups were inoculated by applying $10 \mathrm{ml}$ of spore suspension to the first true leaf per plant as described above. Immediately after inoculation, plants in the second group were also divided into four subgroups (6 plants/subgroup) and exposed to the above-mentioned daily UV-B treatments from the day of inoculation. Plants in the first two groups were exposed to similar daily UV-B treatments as described above until disease severity was recorded 9 days after inoculation.

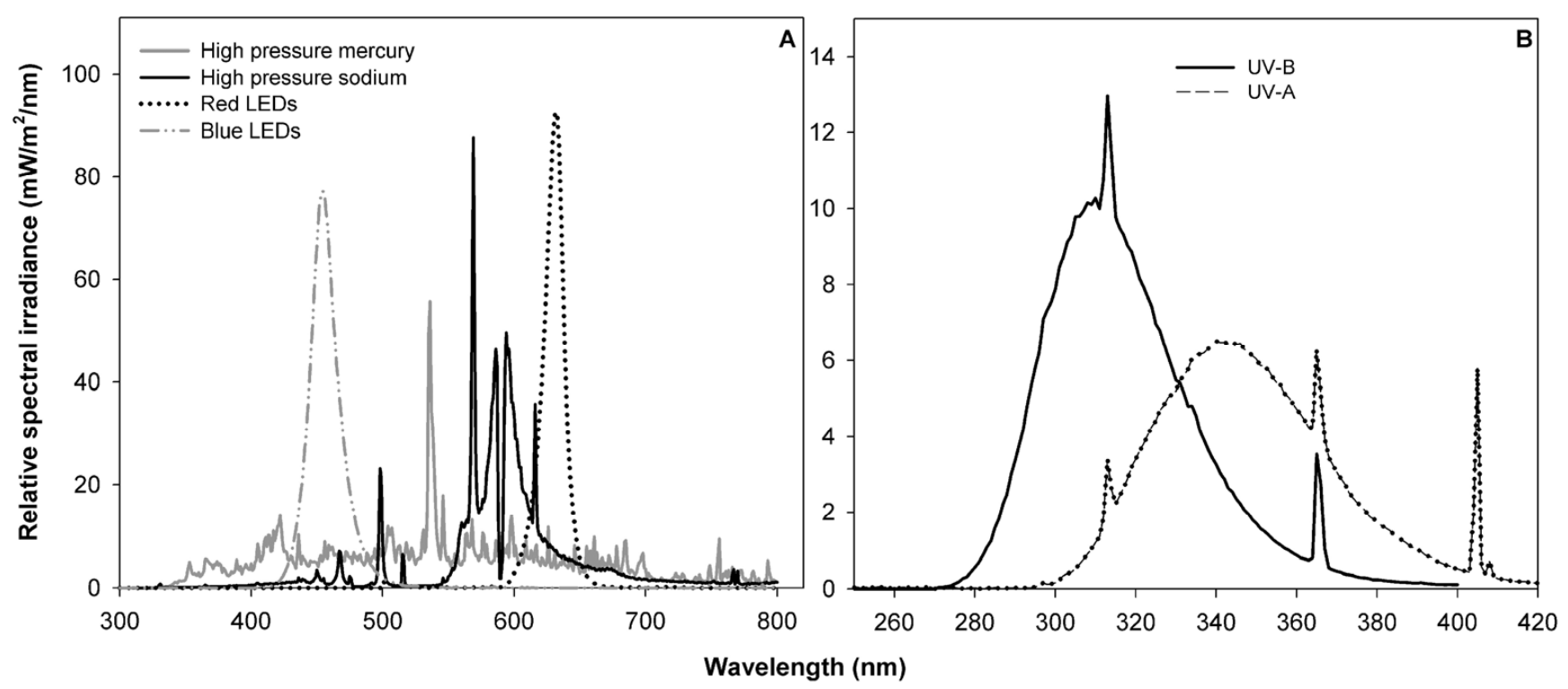

Fig. 1. Spectral distribution measured at 1-nm intervals for the radiation sources of A, high-pressure sodium (HPS) lamps, high-pressure mercury lamps, and red- and bluelight-emitting diodes (LEDs); and B, ultraviolet-A (UV-A) and ultraviolet-B (UV-B) fluorescence tubes. 
Plants in the third group were maintained under 16-h GL conditions without any UV-B exposure for 3 days following inoculation. Then, the plants were divided into four subgroups (6 plants/subgroup) and exposed to the above-mentioned UV-B treatments for 6 days, until assessments for sporulation potential and severity of powdery mildew were done.

Conidial germination and colony development of $P$. xanthii were assessed 3 days after inoculation on plants in groups one and two described above. To do this, leaf disks $(1.8 \mathrm{~cm}$ in diameter) were cut from the inoculated leaves (one leaf disk/plant, four leaf disks/treatment), soaked in 3:1 ethanol/glacial acetic acid (vol/vol) for $3 \mathrm{~h}$ as described previously (45), stained with $5 \%$ acid fuchsin in aqueous lactic acid $(50 \% \mathrm{vol} / \mathrm{vol})$, and examined with a light microscope at $\times 400$ magnification. In all, 50 conidia/leaf disk were assessed. Conidia with germ tubes equal to or longer than the conidial width were counted as germinated. Successful stages of development were categorized as follows: (i) successful infection, wherein a conidium developed more than one primary hyphum or one branched hyphum; and (ii) successful colony development, wherein a conidium produced at least three primary hyphae, two of which had branched. The percentage of colonized leaf area (disease severity) for plants in groups one and two was estimated 9 days after inoculation by visual observation.

To examine the effect of daily UV-B treatment on sporulation potential of $P$. xanthii, four leaf disks, each $1.8 \mathrm{~cm}$ in diameter, were cut from each replicate plant in group three described above 9 days after inoculation. The leaf disks from each plant were placed in separate $50-\mathrm{ml}$ centrifuge tubes (four leaf disks/replicate plant/tube) with $10 \mathrm{ml}$ of sterilized distilled water containing Tween 20 (Sigma-Aldrich Chemie $\mathrm{GmbH}$ ) at $20 \mu \mathrm{l} /$ liter and shaken manually 20 times. The leaf disks were removed, and the number of conidia per milliliter was determined with a hemocytometer for two aliquots/replicate (HYCOR; Hycor Biomedical Inc.). Two independent experiments were conducted with six replicate plants/treatment/experiment. Concentrations of the spore suspensions were $9 \times 10^{3}$ and $5 \times 10^{3}$ conidia/ml in experiments one and two, respectively.

At the end of the experiment, relative flavonoids, maximal photosystem II efficiency (variable fluorescence $[\mathrm{Fv}] /$ maximum fluorescence $[\mathrm{Fm}]$ ), and leaf area were recorded for plants in group one. Relative flavonoids (anthocyanin and flavonol) were measured for the canopy of each plant using a fluorescence excitation ratio method (10) with a handheld Multiplex 3 multi-excitation wavelength chlorophyll fluorometer (Force-A). Three repeated measurements were carried out for each plant canopy. The measurements were standardized with blue foil supplied by the manufacturer. With this standardization, the amount of anthocyanin and flavonols was estimated as the green and UV-A light absorbance relative to the standard blue foil. Fv/Fm and leaf area were measured for the second true leaves of each plant with a portable chlorophyll fluorometer (Plant Efficiency Analyzer; Hansatech Instruments), using excitation light of about $1,500 \mu \mathrm{mol}$ photons $/ \mathrm{m}^{2} / \mathrm{s}$ after $15-\mathrm{min}$ dark adaptation. To do so, intact leaves were first adapted for 15 min in total darkness by using light-weight leaf clips with shutters supplied by the manufacturer. After dark adaptation, the sensor unit of the portable chlorophyll fluorometer was placed over the leaf clip and the shutter was slid open. Powerful illumination $(1,500$ $\mu \mathrm{mol}$ photons $/ \mathrm{m}^{2} / \mathrm{s}$ ) was applied to the exposed portion of the leaf by light-emitting diodes (LEDs) present in the sensor unit, and consequent fluorescence signals were detected. Leaf area was determined using an LI-3100 area meter (LI-COR Inc.).

Efficacy of UV-B against $P$. xanthii at a range of inoculum concentrations. Thirty-two plants, each at the first-true-leaf stage of growth, were inoculated with each of the following conidial suspensions of $P$. xanthii: $5 \times 10^{3}, 2.5 \times 10^{4}, 7 \times 10^{4}$, and $1.6 \times 10^{5}$ conidia/ml of water. Immediately after inoculation, four plants receiving each inoculum concentration were exposed to either $16 \mathrm{~h}$ of GL or $16 \mathrm{~h}$ of GL + UV-B radiation of $1 \mathrm{~W} / \mathrm{m}^{2}$ for $10 \mathrm{~min}$ during the dark period, as described above. The percent leaf area colonized by powdery mildew was assessed 3, 6, 9, and 12 days after inoculation. Four noninoculated control plants were included for each light treatment ( $16 \mathrm{~h}$ of GL or $16 \mathrm{~h}$ of GL $+\mathrm{UV}-\mathrm{B})$ as check plants. Assessments of the inoculated plants ceased once visible symptoms were observed on the noninoculated plants as a result of inoculum spread from the inoculated plants. The experiment was conducted two times.

Effect of full-spectrum background white light on suppression of powdery mildew by UV-B. This experiment was conducted to elucidate the effect of full-spectrum background white light supplied by high-pressure mercury lamps on the efficacy of UV-B for powdery mildew control. Cucumber plants, each bearing one unfolded true leaf, were inoculated with $10 \mathrm{ml}$ of a conidial suspension per leaf per plant, as described above. Immediately after inoculation, plants were exposed to one of the following treatments (eight replicate plants/treatment): (i) $16 \mathrm{~h}$ of GL, (ii) $16 \mathrm{~h}$ of GL followed by $10 \mathrm{~min}$ of UV-B at $1 \mathrm{~W} / \mathrm{m}^{2}$ beginning at the start of the night interval, (iii) $16 \mathrm{~h}$ of GL followed by $2 \mathrm{~h}$ of light supplied by high-pressure mercury lamps $\left(70 \pm 10 \mu \mathrm{mol} / \mathrm{m}^{2} / \mathrm{s}\right)$, and (iv) $16 \mathrm{~h}$ of GL followed by UV-B at $1 \mathrm{~W} / \mathrm{m}^{2}$ plus $2 \mathrm{~h}$ of light supplied by high-pressure mercury lamps $\left(70 \pm 10 \mu \mathrm{mol} / \mathrm{m}^{2} / \mathrm{s}\right)$ beginning at the start of the night interval (Supplementary Figure 2). To avoid interplot interference among treatments, the greenhouse compartment was partitioned with white plastic sheets, as described above. The percent leaf area diseased was assessed 12 days after inoculation for the inoculated leaf on each plant. The experiment was conducted twice, with an inoculum concentration of $5 \times$ $10^{4}$ and $7 \times 10^{4}$ conidia/ml in the first and second experiments, respectively.

Effects of background spectral quality on suppression of cucumber powdery mildew by UV-B. This experiment was conducted to understand the effects of different background spectral qualities on the efficacy of UV-B in powdery mildew disease suppression. Cucumber plants, each bearing one unfolded true leaf, were inoculated with $10 \mathrm{ml}$ of a conidial suspension per leaf per plant $\left(8.4 \times 10^{4}\right.$ conidia $\left./ \mathrm{ml}\right)$. Immediately after inoculation, eight plants were exposed to each of the following treatments: (i) $16 \mathrm{~h}$ of GL, (ii) $16 \mathrm{~h}$ of GL followed by $10 \mathrm{~min}$ of UV-B at $1 \mathrm{~W} / \mathrm{m}^{2}$ beginning at the start of the night interval, (iii) $16 \mathrm{~h}$ of GL plus $2 \mathrm{~h}$ of UV-A $\left(2.2 \mathrm{~W} / \mathrm{m}^{2}\right)$ at the start of the night interval, (iv) $16 \mathrm{~h}$ of GL followed by $10 \mathrm{~min}$ of UV-B at $1 \mathrm{~W} / \mathrm{m}^{2}$ plus $2 \mathrm{~h}$ of UV-A $(2.2$ $\mathrm{W} / \mathrm{m}^{2}$ ) beginning at the start of the night interval, (v) $16 \mathrm{~h}$ of GL followed by $2 \mathrm{~h}$ of blue light $\left(39 \mu \mathrm{mol} / \mathrm{m}^{2} / \mathrm{s}\right)$ beginning at the start of the night interval, (vi) $16 \mathrm{~h}$ of GL followed by $2 \mathrm{~h}$ of blue light $\left(39 \mu \mathrm{mol} / \mathrm{m}^{2} / \mathrm{s}\right.$ ) and $10 \mathrm{~min}$ of UV-B at $1 \mathrm{~W} / \mathrm{m}^{2}$ beginning at the start of the night interval, (vii) $16 \mathrm{~h}$ of GL followed by $2 \mathrm{~h}$ of red light $\left(42 \mu \mathrm{mol} / \mathrm{m}^{2} / \mathrm{s}\right)$ beginning at the start of the night interval, and (viii) $16 \mathrm{~h}$ of GL followed by $2 \mathrm{~h}$ of red light $\left(42 \mu \mathrm{mol} / \mathrm{m}^{2} / \mathrm{s}\right)$ and $10 \mathrm{~min}$ of UV-B at $1 \mathrm{~W} / \mathrm{m}^{2}$ beginning at the start of the night interval (Supplementary Figure 3). UV-A radiation (Fig. 1) was supplied by 120-cm UV-A tubes (Model UVA-340; Q-PANEL Lab Products). Blue light (Fig. 1) was supplied by a GreenPower LED module HF (Philips). Red light (Fig. 1) was supplied by 162-W high-power LED growth lights (Sola-co). The experiment was repeated using a suspension of inoculum with a concentration of $4.3 \times 10^{4}$ conidia/ml.

At 3 days after inoculation, 1.8-cm-diameter leaf disks were collected from leaves exposed to each treatment and assessed for conidial germination, infection, and colonization as described above. The percentage of leaf area diseased was also assessed at 3-day intervals from the time of inoculation until 12 days after inoculation. The area under the disease progress curve (AUDPC) was calculated as described by Campbell and Madden (9) using the following formula:

$$
\mathrm{AUDPC}=\sum_{i=1}^{n} \frac{\left(x_{i}+x_{i-1}\right)}{2}\left(t_{i}-t_{i-1}\right)
$$

where $n$ is the number of evaluation times, $x_{i}$ is disease severity $(\%)$ at the evaluation time $t$, and $\left(t_{i}-t_{i-1}\right)$ is the duration between each assessment.

Effect of UV-B with specific background spectral radiation quality on viability of conidia. This experiment was conducted to 
elucidate whether UV-B in combination with specific background spectral qualities of radiation may kill $P$. xanthii conidia. Sixteen plants, each bearing a single unfolded true leaf, were inoculated with a spore suspension of $P$. xanthii containing $8.4 \times 10^{4}$ conidia/ml, as described above. The plants were incubated in the greenhouse for 5 days under similar temperature and $\mathrm{RH}$ conditions and $16 \mathrm{~h}$ of GL, as described above, to promote sporulation of $P$. xanthii. Plants were then exposed to the eight treatments used in the background radiation experiments (two plants/treatment) over four subsequent days. The inoculated leaf was then removed from each plant and shaken in $50 \mathrm{ml}$ of distilled water to harvest the conidia, from which a 1-ml aliquot of the resultant suspension was added to $1 \mu \mathrm{l}$ of $0.5 \%$ (wt/vol) of the fluorescent vital stain fluorescein diacetate (19) on a glass microscope slide. After 3 min, 100 conidia/slide were examined with a fluorescence microscope ( 325 to $500 \mathrm{~nm}$ excitation filter and transmission filter $>530 \mathrm{~nm}$ ) (35), and the number of conidia exhibiting bright green fluorescence (indicative of viability) was recorded. The experiment was conducted once again as described above but with a spore concentration of $7 \times 10^{4}$ conidia $/ \mathrm{ml}$.

Recording of environmental conditions. Light intensity supplied by mercury, HPS, and red and blue LED lamps at plant height was recorded with a digital Lambda LI-185B photometer (LI-COR Inc.) containing an LI-190 quantum sensor. Spectral qualities of all lamps used in the study were confirmed using an Optronic model 756 spectroradiometer (Optronic Laboratories). Intensity of UV-B irradiance was measured using a SKYE SKU430 sensor (Skye Instruments Ltd.) calibrated for the UV-B sources by an Optronic model 756 spectroradiometer (Optronic Laboratories). The intensity of UV-A was measured with a SKYE SKU426/SS2 38582 sensor (Skye Instruments Ltd.). Air temperature and RH were recorded at 5-min intervals using a Priva greenhouse computer (Priva), with dry and wet bulb thermosensors deployed at the height of the plant canopy.

Data analysis. Analysis of variance was performed using the general linear model procedure (Minitab Version 16.0; Minitab Corp.) with light-UV-B treatments, time of exposure to treatments ( 2 days preinoculation, from the day of inoculation, and 3 days postinoculation), and light-UV-B treatment-time of exposure as fixed factors. Experimental repeats, replicates within experiments, and treatment-experimental repeat interaction all were treated as

Table 1. Effect of different ultraviolet-B radiation doses applied daily during the night on conidial germination and colony development of Podosphaera xanthii on the cucumber 'Confida'

\begin{tabular}{lccc}
\hline & \multicolumn{3}{c}{ Pathogen developmental stage (\%) $^{\mathbf{v}}$} \\
\cline { 2 - 4 } Treatment $^{\mathbf{w}}$ & Germination $^{\mathbf{x}}$ & Infection $^{\mathbf{y}}$ & Colony $^{\mathbf{z}}$ \\
\hline $16 \mathrm{~h} \mathrm{of} \mathrm{GL}$ & $67.0 \pm 2.9 \mathrm{a}$ & $59.1 \pm 3.3 \mathrm{a}$ & $53.0 \pm 3.2 \mathrm{a}$ \\
$1 \mathrm{~W} / \mathrm{m}^{2} \times 5 \mathrm{~min}$ & $49.0 \pm 4.4 \mathrm{~b}$ & $33.5 \pm 3.1 \mathrm{~b}$ & $01.6 \pm 0.8 \mathrm{~b}$ \\
$1 \mathrm{~W} / \mathrm{m}^{2} \times 10 \mathrm{~min}$ & $48.8 \pm 4.8 \mathrm{~b}$ & $17.8 \pm 2.6 \mathrm{c}$ & $00.0 \pm 0.0 \mathrm{~b}$ \\
$1 \mathrm{~W} / \mathrm{m}^{2} \times 15 \mathrm{~min}$ & $51.6 \pm 4.0 \mathrm{~b}$ & $13.8 \pm 3.5 \mathrm{c}$ & $00.0 \pm 0.0 \mathrm{~b}$ \\
\hline
\end{tabular}

${ }^{\mathrm{v}}$ Leaf disks $(1.8 \mathrm{~cm}$ in diameter) were cut 3 days after inoculation of cucumber leaves with P. xanthii; data were pooled from plants exposed to the various treatments starting 2 days before inoculation (four leaf disks/treatment) or at the time of inoculation (four leaf disks/treatment). Leaf disks were treated with ethanol/glacial acetic acid (3:1 [vol/vol] $)$ solution for $3 \mathrm{~h}$ and then stained with lactofuchsin. Fifty conidia were counted per leaf disk. Values represent the mean \pm standard error of two independent experiments with eight replicated leaf disks/treatment/ experiment. Different letters indicate significant differences at $P=0.05$ based on Tukey's means comparison.

${ }^{\mathrm{w}}$ All plants received $16 \mathrm{~h}$ of growth light (GL). Plants exposed only to $16 \mathrm{~h}$ of GL served as a control treatment; the other treatments are explained in the main text.

${ }^{x}$ Conidia with germ tubes equal to or longer than the conidial width were counted as germinated.

${ }^{y}$ More than one primary hyphum or one branched hyphum/conidium were considered evidence of successful infections.

${ }^{\mathrm{z}}$ Successive colony; a conidium that produced three primary hyphae with at least two of the hyphae branched was considered a colony. random factors. Data were checked for homogeneity of variance and normality, transformed as necessary for analysis, and then back-transformed for presentation of results. Treatment means were compared using Tukey's pairwise comparison test at $P=$ 0.05. Mean comparisons were performed separately for each experimental repeat when the experimental repeat-treatment interaction was significant. Regression analyses were performed using SigmaPlot 10 (Systat Software, Inc.).

\section{Results}

Daily duration of UV-B exposure and exposure timing on pathogen development. UV-B light treatment had a significant effect on conidial germination, infection $(P=0.02)$, and colony development $(P=0.001)$ of $P$. xanthii. However, experimental repeat, the initiation time of the UV-B treatment, and the interaction between UV-B treatment and the initiation time of the UV-B treatment did not affect pathogen development significantly. The reduction in infections by $P$. xanthii under UV-B treatments of 5-, 10-, and 15-min durations was 43.3, 70.0, and 76.8\%, respectively, compared with the 16-h GL control treatment (Table 1). The percentage of powdery mildew colonies declined from $53.0 \pm 3.2 \%$ under $16 \mathrm{~h}$ of GL to $<2 \%$ for all UV-B treatments $(P<0.0001)$. The magnitude of the UV-B treatment effect increased significantly $(P<0.0001)$ at each sequentially later stage of pathogen development (i.e., from germination to infection to colony development; Table 1).

Effect of daily duration of UV-B exposure and exposure timing on powdery mildew severity. The UV-B treatment $(P=$ 0.001), timing of the initial UV-B treatment (preinoculation, day of inoculation, and postinoculation exposure; $P<0.0001$ ), and the interaction of these main effects $(P=0.0001)$ all had significant effects on powdery mildew severity. Powdery mildew severity exceeded $80 \%$ on plants exposed only to $16 \mathrm{~h}$ of GL (Fig. 2). When UV-B was applied starting 2 days before or from the day of inoculation, disease severity declined significantly $(P<0.001)$ as UV-B duration increased from 5 to $10 \mathrm{~min}$ (Fig. 2) but there was no further decline when the UV-B exposure duration was increased from 10 to $15 \mathrm{~min}$ (Fig. 2). However, exposure of plants to UV-B starting 2 days before inoculation had no additional effect at suppressing disease than when plants were exposed to the same duration of UV-B starting from the day of inoculation (Fig. 2). When UV-B exposure was not started until 3 days after inoculation, there were sequential decreases in disease severity with each increase in duration of exposure to UV-B (Fig. 2). Regardless of the duration of exposure to UV-B, exposure of plants to UV-B starting 2 days prior to or from the day of inoculation was significantly more effective at suppressing disease severity than exposure of plants to UV-B 3 days after inoculation (Fig. $2 ; P<0.0001$ ). Sporulation of $P$. xanthii colonies on plants exposed to UV-B at $1 \mathrm{~W} / \mathrm{m}^{2} 3$ days after inoculation decreased exponentially with increasing duration of UV-B exposure (Fig. 3A; $P<0.0001$ ).

Effect of daily duration of UV-B exposure and exposure timing on plant growth. Leaf area did not decrease significantly when plants were exposed to $5 \mathrm{~min}$ of UV-B at $1 \mathrm{~W} / \mathrm{m}^{2}$ compared with the 16-h GL control treatment but decreased significantly after $10(P=0.0001)$ or $15 \mathrm{~min}(P<0.0001)$ of exposure to UV-B (Fig. 3B). A quadratic model fit the data best: $Y=537.8+1.8 X-$ $1.1 X^{2}$, where $Y=$ leaf area of the second true leaf (square centimeters) and $X=$ the duration of exposure to UV-B at an intensity of $1 \mathrm{~W} / \mathrm{m}^{2}$ (Fig. 3B). Relative concentration of flavonols was reduced by all UV-B treatments compared with $16 \mathrm{~h}$ of GL, with the greatest reduction in flavonol concentration observed with the longest duration of UV-B exposure (Table 2). Relative concentrations of anthocyanins were reduced by all UV-B treatments compared with the 16-h GL treatment. Photosystem II efficiency (Fv/Fm) was reduced significantly by $15 \mathrm{~min}$ of UV-B exposure compared with shorter exposure or no UV-B exposure (Table 2; $P<0.001$ ).

Efficacy of UV-B at a range of $P$. xanthii inoculum concentrations. Powdery mildew severity increased exponentially as inoculum dose increased on plants exposed only to $16 \mathrm{~h}$ of GL, 
yielding a quadratic model: $Y=23.7+75.1[1-\mathrm{e}(-0.06 X)]$, where $Y=$ percentage leaf area diseased and $X=$ inoculum concentration (Fig. 4). In contrast, disease severity increased only slightly, from 0.6 to $7.5 \%$ across the range of inoculum concentrations tested $(5 \times$ $10^{3}$ to $1.6 \times 10^{5} / \mathrm{ml}$ ), when plants were exposed to $16 \mathrm{~h}$ of GL followed by $10 \mathrm{~min}$ of UV-B at $1 \mathrm{~W} / \mathrm{m}^{2}$ during the dark interval (Fig. 4). Although the increase in disease severity with increasing inoculum concentration was reduced by exposure of plants to UV-B, there was still a significant linear increase in disease severity: $Y=$ $0.22+0.05 X$ at $R^{2}=0.99$ (Fig. 4).

Effect of full-spectrum background white light on suppression of powdery mildew by UV-B. Powdery mildew severity was significantly affected by light treatment $(P<0.0001)$ and experiment repeat $(P=0.047)$ but not by the interaction of light treatment-experiment repeat. Therefore, the results are presented separately for each repeat of the experiment (Fig. 5). Mean powdery mildew severity was reduced significantly (to $0.57 \%$ ) when inoculated cucumber plants were exposed to $16 \mathrm{~h}$ of GL followed by UV-B, relative to inoculated plants only exposed to $16 \mathrm{~h}$ of GL (100\% severity) $(P<0.0001$; Fig. 5, treatments 2 and 1 , respectively). Disease severity was reduced significantly (to $22.5 \%$ ) when UV-B exposure occurred during a 2-h period of lighting supplied by high-pressure mercury lamps compared with the 16-h GL control treatment $(100 \%$ severity $)(P<0.0001$; Fig. 5 , treatments 4

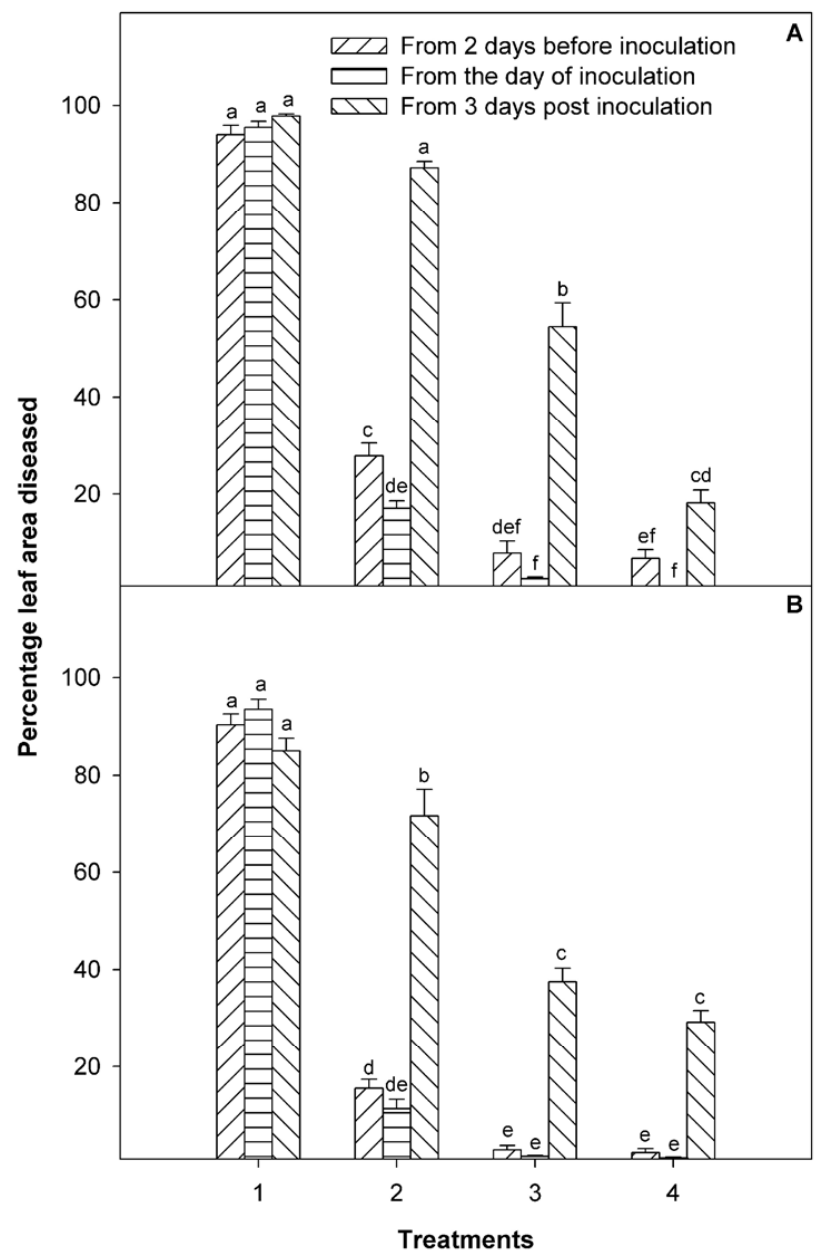

Fig. 2. Severity of powdery mildew caused by Podosphaera xanthii on 'Confida' cucumber exposed to either $16 \mathrm{~h}$ of growth light (GL) (treatment 1), $16 \mathrm{~h}$ of $\mathrm{GL}+5$ min of ultraviolet-B (UV-B) at $1 \mathrm{~W} / \mathrm{m}^{2}$ (treatment 2), $16 \mathrm{~h}$ of GL +10 min of UV-B at $1 \mathrm{~W} / \mathrm{m}^{2}$ (treatment 3), and $16 \mathrm{~h}$ of GL $+15 \mathrm{~min}$ of UV-B at $1 \mathrm{~W} / \mathrm{m}^{2}$ (treatment 4 ) in $\mathbf{A}$, experiment 1 and $\mathbf{B}$, experiment 2. Plants were exposed to treatments from 2 days before inoculation, from the day of inoculation, or from 3 days post inoculation. Percentage of leaf area covered by powdery mildew was assessed 9 days after inoculation. Bars represent mean \pm standard error of disease severity for six replicates. Different letters indicate significant differences at $P=0.05$. and 1, respectively). Disease severity was $76.2 \%$ on plants exposed to $16 \mathrm{~h}$ of GL followed by $2 \mathrm{~h}$ of light supplied by high-pressure mercury lamps (treatment 3) compared with the 16-h GL control treatment $(P<0.001$; Fig. 5). Experimental repeat had a significant effect on severity because significantly greater disease occurred in experiment 2 compared with experiment $1(P<0.00001)$.

Effects of specific background spectral quality on suppression of powdery mildew by UV-B. Germination of $P$. xanthii conidia on inoculated cucumber plants was significantly affected by light treatment $(P<0.00001)$ and experiment repeat $(P=$ 0.033 ), whereas the experiment repeat-treatment interaction was not significant. Numbers of germinated conidia was significantly greater in experiment 2 compared with experiment 1 . Inoculated cucumber plants exposed to $16 \mathrm{~h}$ of GL + UV-B + red light had significantly fewer germinated conidia compared with $16 \mathrm{~h}$ of GL (Fig. 6A, treatment 8 and 1, respectively). Number of conidia germinated under $16 \mathrm{~h}$ of GL was 34.8 in experiment 1 and 37.5 in experiment 2 (Fig. 6A, treatment 1 ). These were significantly reduced to 19.5 in experiment $1(P=0.0058)$ and 21.5 in experiment $2(P=0.0073)$ with $16 \mathrm{~h}$ of GL $+\mathrm{UV}-\mathrm{B}+$ red light (Fig. 6A, treatment 8).

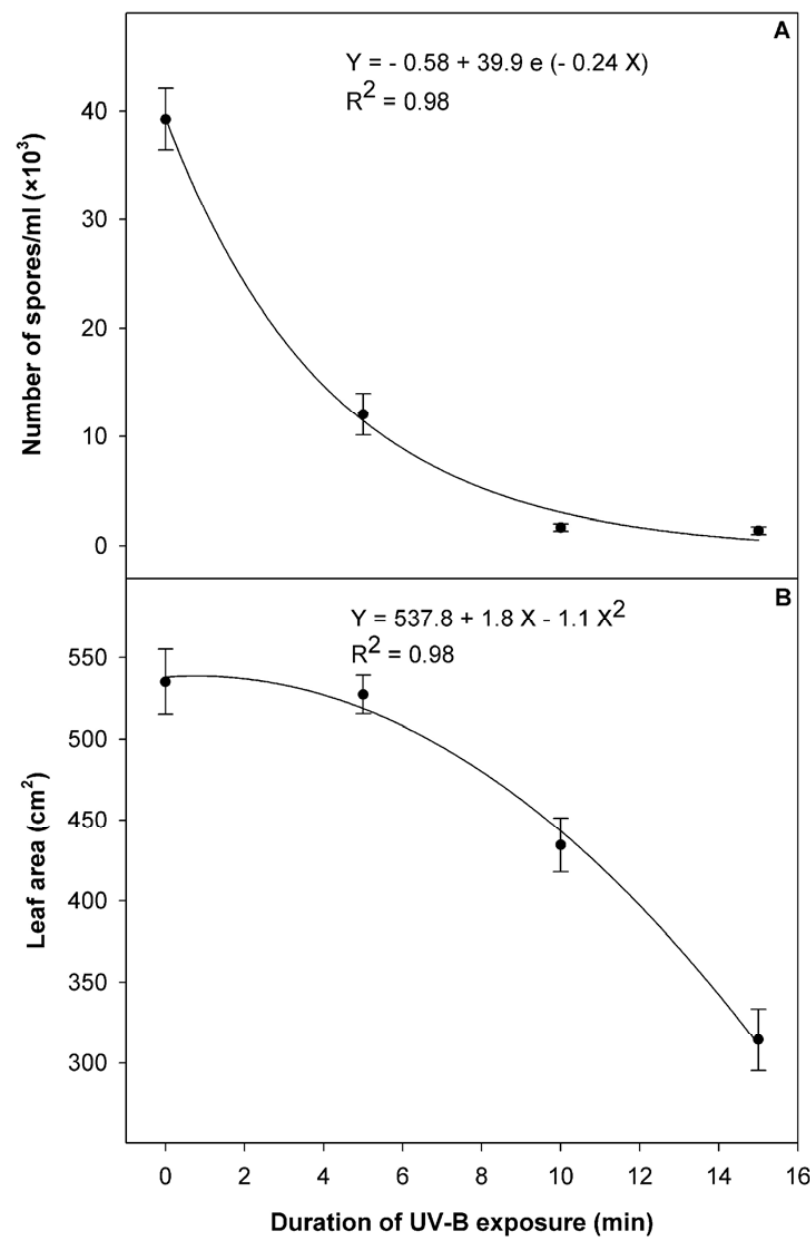

Fig. 3. Relationship between increasing duration of ultraviolet-B (UV-B) treatment and $\mathbf{A}$, spore production by Podosphaera xanthii and $\mathbf{B}$, leaf area of the second true leaves of 'Confida' cucumber. For the spore production experiment, inoculated plants were maintained at $16 \mathrm{~h}$ of growth light (GL) for the first 3 days and then exposed to either $16 \mathrm{~h}$ of GL (0 min UV-B), $16 \mathrm{~h}$ of GL $+5 \mathrm{~min}$ of UV-B, $16 \mathrm{~h}$ of GL +10 min of UV-B, or $16 \mathrm{~h}$ of $\mathrm{GL}+15 \mathrm{~min}$ of UV-B treatments for six days. Number of spore per milliliter was determined for two aliquots/replicate plant. Leaf area measurements were done for plants exposed daily to UV-B treatments for 11 days from the start of experiment. Each value is the mean \pm standard error of two independent experiments with six replicate plants for both sporulation $(n=24)$ and leaf area assessments $(n=12)$. Regression equations: $Y=$ number of spores $/ \mathrm{ml}$ $\left(\times 10^{3}\right)$ in $\mathbf{A}$ and leaf area of the second true leaf (square centimeters) in $\mathbf{B}$, and $X=$ duration of UV-B exposure (minutes). 
The number of infections caused by $P$. xanthii on inoculated cucumber plants was significantly influenced by light treatment $(P<$ 0.0001). Number of $P$. xanthii infections on inoculated cucumber plants was significantly reduced with $16 \mathrm{~h}$ of GL + UV-B + red light compared with $16 \mathrm{~h}$ of GL in both experiments (Fig. 6B, treatments 8 and 1 , respectively). The number of infections on cucumber plants with $16 \mathrm{~h}$ of GL was 32.0 in experiment 1 and 32.3 in experiment 2 . These were reduced to 9.5 in experiment $1(P$ $=0.0002)$ and 10.3 in experiment $2(P=0.0005)$ with treatment 8 . Number of $P$. xanthii infections was reduced with $16 \mathrm{~h}$ of GL + UV-B (treatment 2) only in experiment 2. The number of infections was 32.3 with treatment 1 and was reduced to 14.5 with treatment $2(P=0.03$; Fig. 6B, experiment 2$)$.

Table 2. Relative content of flavonoids (flavonol and anthocyanin) and the chlorophyll fluorescence parameter (variable fluorescence $[\mathrm{Fv}] /$ maximum fluorescence $[\mathrm{Fm}]$ ) of 'Confida' cucumber inoculated with conidia of Podosphaera xanthii after exposure to different doses of ultraviolet (UV)-B radiation in greenhouse experiments ${ }^{\mathrm{w}}$

\begin{tabular}{lccl}
\hline Treatment $^{\mathbf{x}}$ & Flavonol $^{\mathbf{y}}$ & Anthocyanin $^{\mathbf{y}}$ & \multicolumn{1}{c}{ Fv/Fm $^{\mathbf{z}}$} \\
\hline $16 \mathrm{~h} \mathrm{of} \mathrm{GL}$ & $1.536 \pm 0.040 \mathrm{a}$ & $0.928 \pm 0.003 \mathrm{a}$ & $0.792 \pm 0.003 \mathrm{a}$ \\
$1 \mathrm{~W} / \mathrm{m}^{2} \times 5 \mathrm{~min}$ & $1.409 \pm 0.040 \mathrm{~b}$ & $0.920 \pm 0.003 \mathrm{~b}$ & $0.791 \pm 0.002 \mathrm{a}$ \\
$1 \mathrm{~W} / \mathrm{m}^{2} \times 10 \mathrm{~min}$ & $1.341 \pm 0.030 \mathrm{~b}$ & $0.917 \pm 0.002 \mathrm{~b}$ & $0.786 \pm 0.003 \mathrm{ab}$ \\
$1 \mathrm{~W} / \mathrm{m}^{2} \times 15 \mathrm{~min}$ & $1.188 \pm 0.020 \mathrm{c}$ & $0.920 \pm 0.003 \mathrm{~b}$ & $0.773 \pm 0.006 \mathrm{~b}$ \\
\hline
\end{tabular}

${ }^{\mathrm{w}}$ Each value is the mean \pm standard error of two independent experiments with six replicate plants/treatment/experiment. Different letters within each column indicate significant differences at $P=0.05$ based on Tukey's means comparison.

${ }^{x}$ All plants received $16 \mathrm{~h}$ of growth light (GL). Plants exposed only to $16 \mathrm{~h}$ of GL served as a control treatment; the other treatments are explained in the main text.

${ }^{y}$ Measurements were performed 11 days after the start of exposure to UV$\mathrm{B}$, using a Multiplex 3 multi-excitation wavelength chlorophyll fluorometer with the fluorescence excitation ratio method (10). Three repeated measurements were carried out for the canopy of each plant. Values are relative to the blue standard provided by the manufacturer (Force-A).

${ }^{\mathrm{z}}$ Recorded with a portable chlorophyll fluorometer using excitation light of $1,500 \mu \mathrm{mol} / \mathrm{m}^{2} / \mathrm{s}$ after $15 \mathrm{~min}$ of dark adaptation, as described in the main text. Two measurements were done for the second true leaves of each plant.

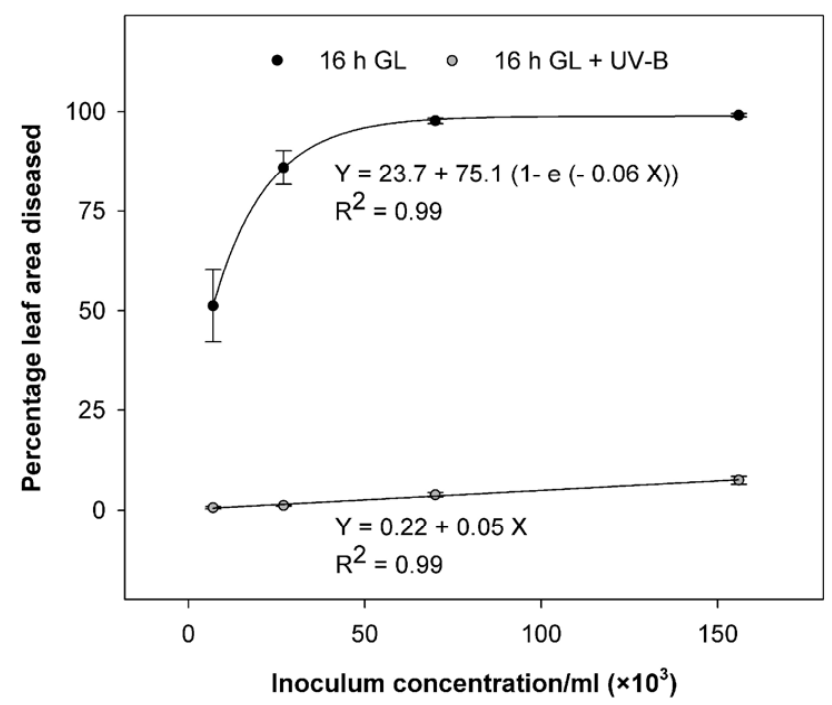

Fig. 4. Relationship between increasing inoculum concentration and severity of powdery mildew on cucumber caused by Podosphaera xanthii 12 days after inoculation. Plants were inoculated by spraying $10 \mathrm{ml}$ of a spore suspension at four different inoculum concentrations (from $5 \times 10^{3}$ to $1.6 \times 10^{5}$ conidia/ml), and were then exposed to treatments of either $16 \mathrm{~h}$ of growth light (GL) or $16 \mathrm{~h}$ of $\mathrm{GL}+10$ min of ultraviolet-B (UV-B) at $1 \mathrm{~W} / \mathrm{m}^{2}$. Each value is the mean \pm standard error of two independent experiments, with four replicate plants in each $(n=8)$. Regression equations with $Y=$ percentage leaf area diseased and $X=$ inoculum concentration $/ \mathrm{ml}\left(\times 10^{3}\right)$.
Number of $P$. xanthii colonies was significantly affected by light treatment $(P<0.0001)$ and experiment repeat-treatment interaction $(P<0.0001)$. All treatments with UV-B (treatments $2,4,6$, and 8 ) and $16 \mathrm{~h}$ of GL + red light (treatment 7 ) significantly reduced the number of $P$. xanthii colonies independent of experimental repeat. The number of colonies on cucumber plants exposed to the $16-\mathrm{h}$ GL treatment was 28.3 in experiment 1 , and none of the conidia developed colonies within 3 days for all treatments that included UV-B $(P<0.0001$; Fig. 6C, experiment 1$)$. The number of colonies was reduced to 8.8 in experiment $1(P=0.0002)$ with treatment 7 (Fig. 6C).

The number of colonies on cucumber plants exposed to the 16-h GL treatment was 30.0 in experiment 2 , and none of the conidia developed colonies within 3 days for cucumber plants subjected to treatments 2 and $8(P<0.0001)$. The number of colonies on cucumber plants exposed to $16 \mathrm{~h}$ of GL $+\mathrm{UV}-\mathrm{B}+\mathrm{UV}-\mathrm{A}$ (treatment 4) was $3.8(P<0.0001)$, was $6.5(P<0.0001)$ on cucumber plants exposed to $16 \mathrm{~h}$ of GL + UV-B + blue light (treatment 6 ), and was $13.0(P=0.019)$ on plants subjected to $16 \mathrm{~h}$ of $\mathrm{GL}+$ red light (treatment 7) (Fig. 6C, experiment 2).

Experimental repeat $(P<0.0001)$, light treatment $(P<0.0001)$, and experiment repeat-treatment interaction $(P=0.005)$ all significantly influenced AUDPC values. AUDPC for plants in experiment 1 was greater than in experiment 2 . Independent of experiment repeat, AUDPC was significantly reduced by all treatments that included UV-B (Fig. 7, treatments 2, 4, 6, and 8) and treatment 7 (16 h of GL + red light). In experiment 1 , AUDPC was 555.0 with $16 \mathrm{~h}$ of GL (treatment 1) and was reduced to 38.3 by treatment 2, 149.3 by treatment $4,209.3$ by treatment $6,6.9$ by treatment 8 , and 338.8 by treatment $7(P<0.0001)$. In experiment 2 , AUDPC was 473.8 on plants exposed to $16 \mathrm{~h}$ of GL (treatment 1 ) and was reduced to 19.1 by treatment $2,109.7$ by treatment $4,140.6$ by treatment $6,6.0$ by treatment 8 , and 235.7 by treatment $7(P<0.0001)$. AUDPC (384.9) was significantly reduced by treatment 5 with $16 \mathrm{~h}$

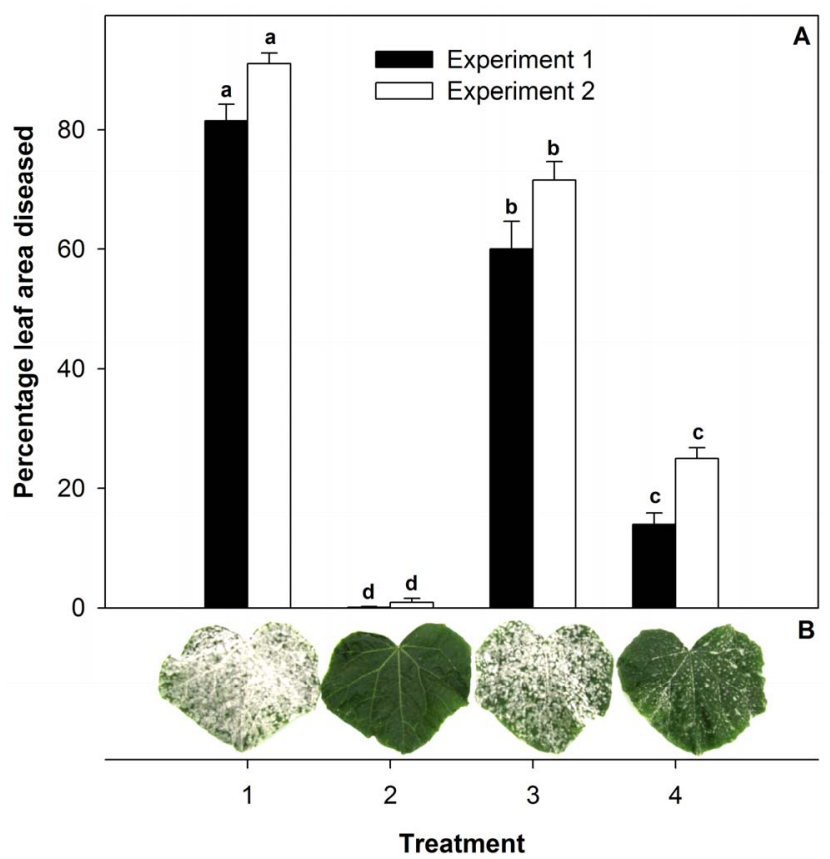

Fig. 5. Effect of ultraviolet-B (UV-B) with full-spectrum background white light or end-of-day full-spectrum white light supplied by high-pressure mercury lamps on $\mathbf{A}$, severity of powdery mildew 12 days after inoculation with Podosphaera xanthii and B, representative diseased leaves of the 'Confida' cucumber. Plants were inoculated by applying $10 \mathrm{ml}$ of spore suspension/leaf/plant onto the first unfolded true leaves, then exposing the plants immediately to treatments of $16 \mathrm{~h}$ of growth light (GL) (treatment 1), $16 \mathrm{~h}$ of GL + UV-B (treatment 2), $16 \mathrm{~h}$ of GL $+2 \mathrm{~h}$ of light supplied by high-pressure mercury lamps (treatment 3 ), or $16 \mathrm{~h}$ of $\mathrm{GL}+\mathrm{UV}-\mathrm{B}+2 \mathrm{~h}$ of light supplied by high-pressure mercury lamps (treatment 4). Each value is the mean \pm standard error of powdery mildew severity for 8 replicate plants. Different letters indicate significant differences within each experiment at $P=0.05$. 
of GL + blue light $(P=0.034)$ compared with treatment 1 with 16 $\mathrm{h}$ of GL, but only in experiment 2 . Viability of the conidia produced under different UV/light treatments was not affected by any of the treatments (data not shown).

\section{Discussion}

Previous reports have shown that development of powdery mildews can be affected by day length, light quality, and UV-B radiation (45,47-50). In this study, the impact of UV-B radiation on severity of cucumber powdery mildew was explored. UV-B radiation inhibited development of $P$. xanthii in a dose-dependent manner. Notably, brief exposure to UV-B radiation $\left(1 \mathrm{~W} / \mathrm{m}^{2}\right.$ for 5 min) during the night greatly enhanced the impact of UV-B on pathogen establishment and growth, and enabled the use of a reduced dose of UV-B with the same degree of efficacy compared with UV-B exposure during the day time. The ability to use a reduced dose of UV-B during the night obviates one of the principle limitations of the use of UV radiation to control powdery mildews: UV doses that are lethal to the pathogen are often phytotoxic to the host plant (15). This study also demonstrated that red light can enhance the deleterious effects of UV-B on $P$. xanthii, further reducing the dose of UV-B required to achieve a given degree of suppression.

Powdery mildew fungi occupy a unique ecological niche. With the exception of the intracellular haustoria, most members of the group (except those of the tribe Phyllactinieae) are wholly external to the host (16). Despite their lack of protective pigmentation in all cells except those of the outer ascocarp wall, powdery mildew fungi persist in an environment that maximizes direct exposure to UV radiation (14). Although generally favored by shading, the results indicate that specific wavelengths, notably UV-A and blue light, are involved in the ability of $P$. xanthii to withstand exposure to UV-B, possibly through the regulation of pathways involved in repair of DNA damaged by exposure to UV-B (13). UV-B has been shown to have deleterious effects on membrane proteins, DNA, photosystem II, enzyme synthesis, and production of growth regulators, and also acts indirectly upon cells through the formation of reactive oxygen species $(6,7,11,12,30)$. Absorption of UV-B photons by DNA bases has been shown to induce two major products indicative of damage to DNA: cyclobutane-pyrimidine dimers and pyrimidine-pyrimidine dimers $(13,25)$. The dimers block the action of DNA polymerase and thereby prevent genome replication $(21,43)$. Photoreactivation or photorepair reverses cyclobutane pyrimidine dimers into the intact monomer bases, and is catalyzed by a light-dependent photolyase enzymatic process (13).

The intensity and composition of photosynthetic active radiation (PAR), particularly wavelengths containing the blue to UV-A range $(5,8,41)$, significantly impact photorepair of DNA damaged by UVB. Ambient PAR of 1,000 to $1,600 \mu \mathrm{mol} / \mathrm{m}^{2} / \mathrm{s}$ ameliorated the effects of UV-B radiation levels as great as $18 \mathrm{~kJ} / \mathrm{m}^{2} /$ day (1). Photolysis involved in DNA repair proceeded during exposure to white light (5) but activity was attributed to a wavelength centered on $400 \mathrm{~nm}$ in cucumber and sorghum (18). In this study, reduced efficiency of UV-B against powdery mildew under UV-A or blue background radiation was observed compared with the degree of suppression observed when UV-B exposure took place during the night. Considering all of the foregoing, it seems reasonable in this study that UV-B radiation damaged the DNA of $P$. xanthii, that blue and UV-A radiation were involved in DNA repair, and that red light exacerbated damage to DNA. Recently, the expression of genes similar to phytochrome, cryptochrome, white collar, and photolyase (light-dependent DNA repair) was confirmed using next-generation sequencing in Erysiphe necator (46). From a practical point of view, the exact mechanism involved is largely irrelevant to application of the findings. Brief exposure of cucumber plants to UV-B radiation during the night, especially when applied with red light, greatly enhanced suppression of $P$. xanthii.

Previous studies have focused upon the stimulation of plant defense mechanisms by UV radiation (e.g., induced resistance in plants has been attributed to elevated flavonoid content of tissues) $(29,34)$. Exposure of strawberry plants to $10 \mathrm{~kJ} / \mathrm{m}^{2} /$ day induced expression of a putative defense gene coding for production of chitinase (23). The putative defense compound $\beta$-1,3-glucanase

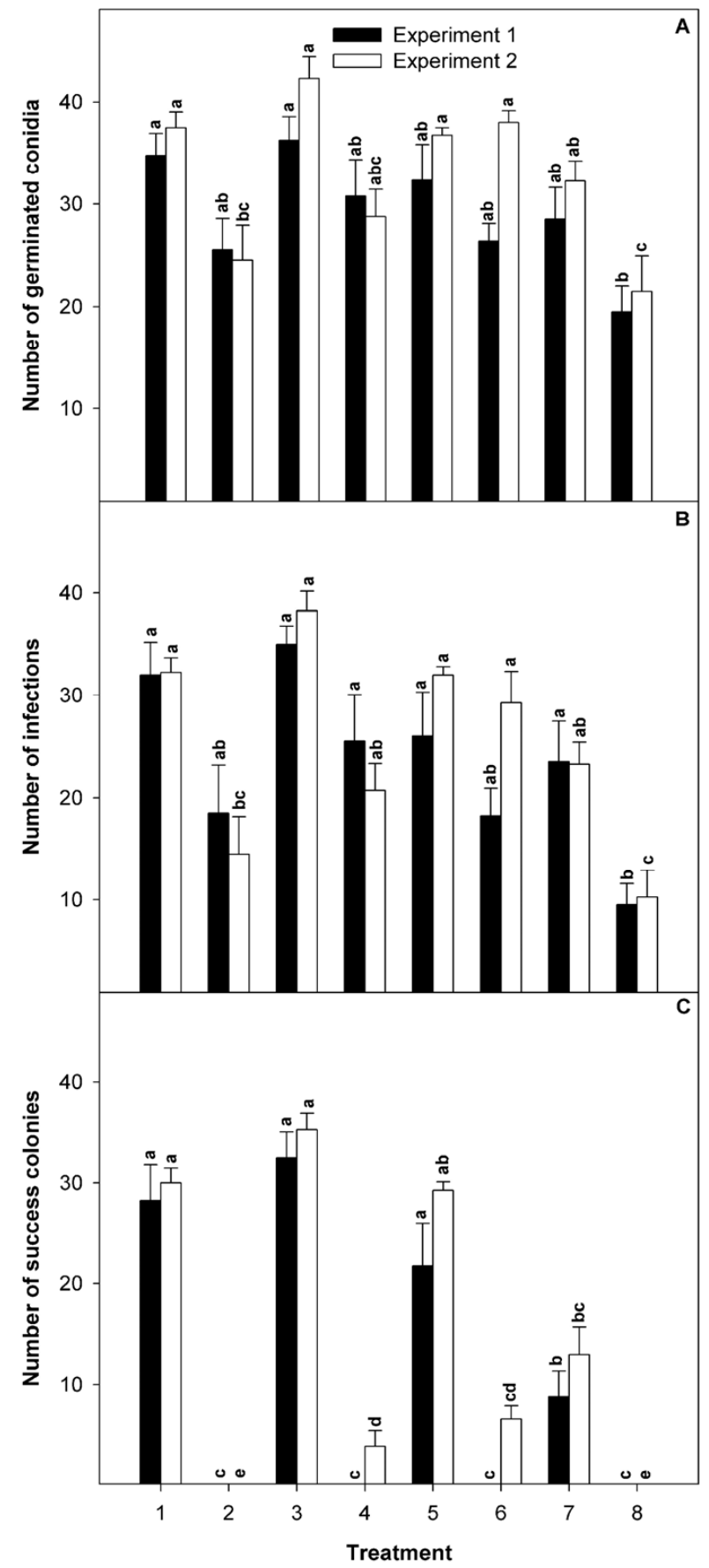

Fig. 6. Effect of specific background radiation quality on the efficiency of ultravioletB (UV-B) radiation on A, conidial germination; B, infection; and C, development of colonies of Podosphaera xanthii on the cucumber 'Confida'. Inoculated plants were immediately exposed to treatments of either $16 \mathrm{~h}$ of growth light $(\mathrm{GL})$ (treatment 1 ), $16 \mathrm{~h}$ of GL + UV-B (treatment 2), $16 \mathrm{~h}$ of GL + UV-A (treatment 3), $16 \mathrm{~h}$ of GL + UV$\mathrm{B}+\mathrm{UV}-\mathrm{A}$ (treatment 4), $16 \mathrm{~h}$ of GL + blue (treatment 5), $16 \mathrm{~h}$ of GL + UV-B + blue (treatment 6 ), $16 \mathrm{~h}$ of $\mathrm{GL}+$ red (treatment 7 ), or $16 \mathrm{~h}$ of $\mathrm{GL}+\mathrm{UV}-\mathrm{B}+$ red (treatment 8). Leaf disks (1.8 cm in diameter) were cut 3 days after exposure of plants to the appropriate treatment, treated with ethanol/glacial acetic acid (3:1) for $3 \mathrm{~h}$, and stained with lactofuchsin. Fifty conidia were assessed for germination, infection, and development of powdery mildew colonies. Each value is the mean \pm standard error of four replicate plants. Different letters indicate significant differences within each experiment at $P=0.05$. Data (number of germinated conidia, number of infection, and $1+$ number of colonies) were log-transformed prior to analysis to induce homogeneity of variances, and the back-transformed data are presented. 


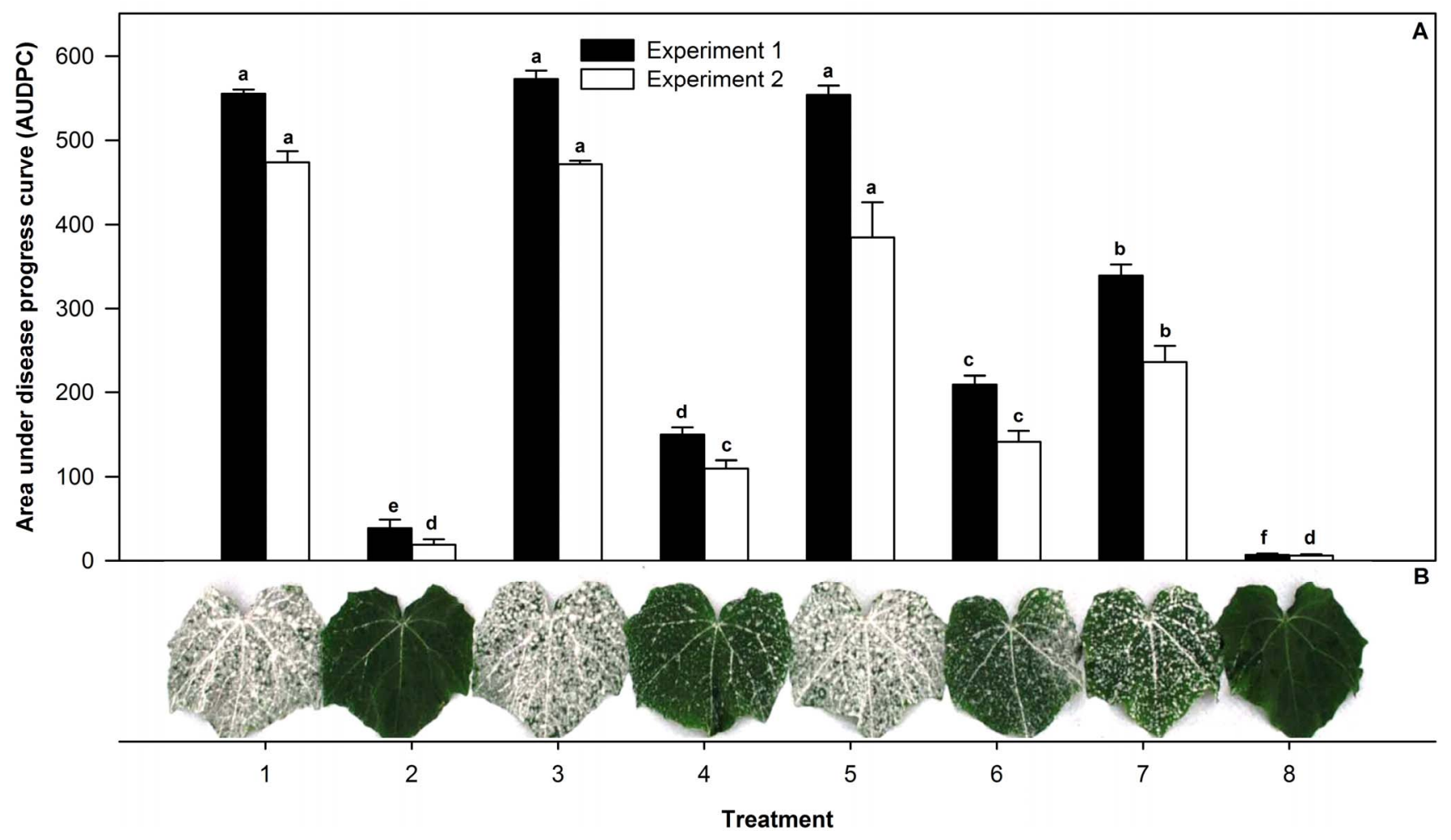

Fig. 7. Effect of ultraviolet-B (UV-B) radiation with different background or end-of-day light qualities on A, area under the disease progress curve and B, severity of powdery mildew on representative leaves 12 days after inoculation with Podosphaera xanthii on the cucumber 'Confida'. Plants were inoculated by applying $10 \mathrm{ml}$ of a spore suspension to the first unfolded true leaves, and exposing the plants immediately thereafter to treatments of either $16 \mathrm{~h}$ of growth light (GL) (treatment 1 ), $16 \mathrm{~h}$ of $\mathrm{GL}+\mathrm{UV}-\mathrm{B}$ (treatment 2), $16 \mathrm{~h}$ of GL + UV-A (treatment 3), $16 \mathrm{~h}$ of GL + UV-B + UV-A (treatment 4), $16 \mathrm{~h}$ of GL + blue (treatment 5), $16 \mathrm{~h}$ of GL + UV-B + blue (treatment 6 ), $16 \mathrm{~h}$ of GL + red (treatment 7), or $16 \mathrm{~h}$ of GL + UV-B + red (treatment 8). Percent diseased leaf area was assessed at 3-day intervals from the time of inoculation to 12 days after inoculation. Each value is the mean \pm standard error of eight replicate plants. Different letters indicate significant differences within each experiment at $P=0.05$. Data were square root-transformed prior to analysis to induce homogeneity of variances, and the back-transformed data are presented.

was induced in French bean (Phaseolus vulgaris) exposed to UV-B (21) but flavonoid biosynthesis was reduced by short-wavelength (275-nm) UV radiation exposure (26). Preinoculation exposure of Arabidopsis thaliana to UV-C radiation resulted in reduced levels of downy mildew for up to 1 week after exposure (27). Many, if not most, of the foregoing putative defense compounds are also associated with plant stress (35). This is especially relevant to the growth of biotrophic plant pathogens, and powdery mildew fungi in particular (35). These results suggest that the involvement of putative plant defense compounds in suppression of powdery mildews be interpreted cautiously, because results could be attributed as definitively to plant stress as to induced resistance to disease. For example, at the levels of UV-B radiation used in this study, the flavonoid content was reduced significantly by UV-B compared with the 16-h GL control treatment, and the greatest flavonoid levels along with the greatest disease levels were found in plants exposed to $16 \mathrm{~h}$ of GL. It is possible that the reduced flavonoid content of tissues exposed to UV-B reflected the relatively low and, thereby, nonphytotoxic dose employed, and the elevated flavonoid content of tissues exposed to $16 \mathrm{~h}$ of GL reflected stress from the severe level of infection by $P$. xanthii. These results indicate that the principal effects of UV-B exposure on suppression of $P$. xanthii are through direct damage to the pathogen. A similar direct effect of UV-B upon disease suppression without evidence of stimulated, long-lasting host defenses was reported in previous work on powdery mildew of rose (45).

\section{Acknowledgments}

This research was financed by the Norwegian Research Council (NRC), the Norwegian Growers' Association (NGF), and the United States Department of Agriculture Specialty Crops Research Initiative (SCRI) Block Grants Program for New York State. We thank technicians at the Centre for Plant Research (SKP) and the Norwegian Institute for Agricultural and Environmental Research, Plant Health and Plant Protection Division; and E. Ørmen for her assistance in scanning electron microscopy.

\section{Literature Cited}

1. Adamse, P., and Britz, S. J. 1992. Amelioration of UV-B damage under high irradiance I. Role of photosynthesis. Photochem. Photobiol. 56:645-650.

2. Austin, C. N., Meyers, J., Grove, G. G., and Wilcox, W. F. 2011 Quantification of powdery mildew severity as a function of canopy variability and associated impacts on sunlight penetration and spray coverage within the fruit zone. Am. J. Enol. Vitic. 62:23-31.

3. Blaustein, A. R., and Sengsavanh, N. 2003. Ultraviolet radiation. Pages 723-732 in: Encyclopedia of Biodiversity, Vol. 5. S. A. Levin, ed. Elsevier, New York.

4. Braun, U. 1995. The Powdery Mildews (Erysiphales) of Europe. Gustav Fischer, Jena, Germany.

5. Britt, A., and Fiscus, E. L. 2003. Growth responses of Arabidopsis DNA repair mutants to solar irradiation. Physiol. Plant. 118:183-192.

6. Caldwell, M. M., Ballare, C. L., Bornman, J. F., Flint, S. D., Bjorn, L. O., Teramura, A. H., Kulandaivelu, G., and Tevini, M. 2003. Terrestrial ecosystems, increased solar ultraviolet radiation and interactions with other climatic change factors. Photochem. Photobiol. Sci. 2:29-38.

7. Caldwell, M. M., Bjorn, L. O., Bornman, J. F., Flint, S. D., Kulandaivelu, G., Teramura, A. H., and Tevini, M. 1998. Effects of increased solar ultraviolet radiation on terrestrial ecosystems. J. Photochem. Photobiol. 46:4052.

8. Caldwell, M. M., Flint, S. D., and Searles, P. S. 1994. Spectral balance and UV-B sensitivity of soybean: A field experiment. Plant Cell. Environ. 17:267-276.

9. Campbell, C. L., and Madden, L. V. 1990. Introduction to Plant Disease Epidemiology. Wiley-Interscience, New York.

10. Cerovic, Z. G., Moise, N., Agati, G., Latouche, G., BenGhozlen, N., and Meyer, S. 2008. New portable optical sensors for the assessment of winegrape phenolic maturity based on berry fluorescence. J. Food Compos. Anal. 21:650-654.

11. Choi, B. Y., and Roh, K. S. 2003. UV-B radiation affects chlorophyll and activation of Rubisco by Rubisco activase in Canavalia ensiformis L. leaves. J. Plant Biol. 46:117-121.

12. Fiscus, E. L., and Booker, F. L. 1995. Is increased UV-B a threat to crop photosynthesis and productivity? Photosynth. Res. 43:81-92.

13. Frohnmeyer, H., and Staiger, D. 2003. Ultraviolet-B radiation-mediated responses in plants. Balancing damage and protection. Plant Physiol. 133:1420-1428.

14. Gadoury, D. M., Cadle-Davidson, L., Wilcox, W. F., Dry, I. B., Seem, R. C., 
and Milgroom, M. G. 2012. Grapevine powdery mildew (Erysiphe necator): A fascinating system for the study of the biology, ecology, and epidemiology of an obligate biotroph. Mol. Plant Pathol. 13:1-16.

15. Gadoury, D. M., Pearson, R. C., Seem, R. C., Henick-Kling, T., Creasy, L. L., and Michaloski, A. 1992. Control of diseases of grapevine by shortwave ultraviolet light. (Abstr.) Phytopathology 82:243.

16. Glawe, D. A. 2008. The powdery mildews: A review of the world's most familiar (yet poorly known) plant pathogens. Annu. Rev. Phytopathol. 46:27-51.

17. Griebel, T., and Zeier, J. 2008. Light regulation and day time dependency of inducible plant defenses in Arabidopsis-phytochrome signalling controls systemic acquired resistance rather than local defense. Plant Physiol. 147:790-801.

18. Hada, M., Iida, Y., and Takeuchi, Y. 2000. Action spectra of DNA photolyases for photorepair of cyclobutane pyrimidine dimers in sorghum and cucumber. Plant Cell Physiol. 41:644-648.

19. Hassan, M., Corkidi, G., Galindo, E., Flores, C., and Serrano-Carreon, L. 2002. Accurate and rapid viability assessment of Trichoderma harzianum using fluorescence-based digital image analysis. Biotechnol. Bioeng. 80:677-684.

20. Hollomon, W. D., and Wheeler, E. I. 2002. Controlling powdery mildews with chemistry. Pages 249-255 in: The Powdery Mildews. A Comprehensive Treatise. R. R. Belanger, R. W. Bushnell, J. A. Dick, and W. L. T. Carver, eds. American Phytopathological Society, St. Paul, MN.

21. Jenkins, G. J. S., Burlinson, B., and Parry, J. M. 2000. The polymerase inhibition assay: A methodology for the identification of DNA-damaging agents. Mol. Carcinogen. 27:289-297.

22. Kangasjarvi, S., Neukermans, J., Li, S., Aro, E., and Noctor, G. 2012. Photosynthesis, photorespiration, and light signalling in defence responses. J. Exp. Bot. 63:1619-1636.

23. Kanto, T., Matsuura, K., Yamada, M., Usami, T., and Amemiya, Y. 2009. UV-B radiation for control of strawberry powdery mildew. Acta Hortic. 842:359-362.

24. Karpinski, S., Gabrys, H., Mateo, A., Karpinska, B., and Mullineaux, P. M. 2003. Light perception in plant disease defence signalling. Curr. Opin. Plant Biol. 6:390-396.

25. Kobayashi, N., Katsumi, S., Imoto, K., Nakagawa, A., Miyagawa, S., Furumura, M., and Mori, T. 2001. Quantitation and visualization of ultraviolet-induced DNA damage using specific antibodies: Application to pigment cell biology. Pigment Cell Res. 14:94-102.

26. Kucera, B., Leubner-Metzger, G., and Wellmann, E. 2003. Distinct ultraviolet-signaling pathways in bean leaves. DNA damage is associated with $\beta$ 1,3-glucanase gene induction, but not with flavanoid formation. Plant Physiol. 133:1445-1452.

27. Kunz, B. A., Dando, P. K., Grice, D. M., Mohr, P. G., Schenk, P. M., and Cahill, D. M. 2008. UV-induced DNA damage promotes resistance to the biotrophic pathogen Hyaloperonospora parasitica in Arabidopsis. Plant Physiol. 148:1021-1031.

28. Lebeda, A., Sedlakova, B., and Kristkova, E. 2007. Temporal changes in pathogenicity structure of cucurbit powdery mildew populations. Acta Hortic. 731:381-388.

29. Lo, C., Coolbaugh, R. C., and Nicholson, R. L. 2002. Molecular characterization and in silico expression analysis of a chalcone synthase gene family in Sorghum bicolor. Physiol. Mol. Plant Pathol. 61:179-188.

30. Mackerness, S. A. H., John, C. F., Jordan, B., and Thomas, B. 2001. Early signaling components in ultraviolet-B responses: Distinct roles for different reactive oxygen species and nitric oxide. FEBS Lett. 489:237-242.

31. McDonald, B. A., and Linde, C. 2002. Pathogen population genetics, evolutionary potential, and durable resistance. Annu. Rev. Phytopathol. 40:349379.

32. McGrath, M. T. 2001. Fungicide resistance in cucurbit powdery mildew: Experiences and challenges. Plant Dis. 85:236-245.

33. McGrath, M. T., Staniszewska, H., and Shishkoff, N. 1996. Fungicide sensitivity of Sphaerotheca fuliginea populations in the United States. Plant Dis. 80:697-703.

34. Modolo, L. V., Cunha, F. Q., Braga, M. R., and Salgado, I. 2002. Nitric oxide synthase-mediated phytoalexin accumulation in soybean cotyledons in response to the Diaporthe phaseolorum $\mathrm{f}$. sp. meridionalis elicitor. Plant Physiol. 130:1288-1297.

35. Moyer, M. M., Gadoury, D. M., Cadle-Davidson, L., Dry, I. B., Magarey, P. A., Wilcox, W. F., and Seem, R. C. 2010. Effects of acute low-temperature events on development of Erysiphe necator and susceptibility of Vitis vinifera. Phytopathology 100:1240-1249.

36. Newsham, K. K., Oxborough, K., White, R., Greenslade, P. D., and McLeod, A. R. 2000. UV-B radiation constrains the photosynthesis of Quercus robur through impacts on the abundance of Microsphaera alphitoides. For. Pathol. 30:265-275.

37. Nicot, P. C., Mermier, M., and Vaissiere, B. E. 1996. Differential spore production by Botrytis cinerea on agar medium and plant tissue under nearultraviolet light-absorbing polyethylene film. Plant Dis. 80:555-558.

38. Perez-Garcia, A., Romero, D., Fernandez-Ortuno, D., Lopez-Ruiz, F., De Vicente, A., and Tores, J. A. 2009. Pathogen profile-the powdery mildew fungus Podosphaera fusca (synonym Podosphaera xanthii), a constant threat to cucurbits. Mol. Plant Pathol. 10:153-160.

39. Reuveni, R., and Raviv, M. 1992. The effect of spectrally-modified polyethylene films on the development of Botrytis cinerea in greenhouse-grown tomato plants. Biol. Agric. Hortic. 9:77-86.

40. Roberts, M. R., and Paul, N. D. 2006. Seduced by the dark side: Integrating molecular and ecological perspectives on the influence of light on plant defence against pests and pathogens. New Phytol. 170:677-699.

41. Sancar, A. 1994. Structure and function of DNA photolyase. Biochemistry $33: 2-9$

42. Schuerger, A. C., and Brown, C. S. 1997. Spectral quality affects disease development of three pathogens on hydroponically grown plants. HortScience 32:96-100.

43. Sinha, R. P., Dautz, M., and Hader, D. P. 2001. A simple and efficient method for the quantitative analysis of thymine dimers in cyanobacteria, phytoplankton and macroalgae. Acta Protozool. 40:187-195.

44. Suthaparan, A., Stensvand, A., Solhaug, K. A., Torre, S., Mortensen, L. M., Gadoury, D. M., and Gislerød, H. R. 2012. Interruption of the night period by UV-B suppresses powdery mildew of rose and cucumber. Acta Hortic. 956:617-620.

45. Suthaparan, A., Stensvand, A., Solhaug, K. A., Torre, S., Mortensen, L. M., Gadoury, D. M., Seem, R. C., and Gislerød, H. R. 2012. Suppression of powdery mildew (Podosphaera pannosa) in greenhouse roses by brief exposure to supplemental UV-B radiation. Plant Dis. 96:1653-1660.

46. Suthaparan, A., Stensvand, A., Solhaug, K. A., Torre, S., Telfer, K. H., Ruud, A. K., Cadle-Davidson, L., Mortensen, L. M., Gadoury, D. M., Seem, R. C., and Gislerød, H. R. 2012. Suppression of cucumber powdery mildew by UV-B is affected by background light quality. (Abstr.) Phytopathology 102:S4.116.

47. Suthaparan, A., Stensvand, A., Torre, S., Herrero, M., L., Pettersen, R. I., Gadoury, D. M., and Gislerød, H. R. 2010. Continuous lighting reduces conidial production and germinability in the rose powdery mildew pathosystem. Plant Dis. 94:339-344.

48. Suthaparan, A., Torre, S., Stensvand, A., Herrero, M. L., Pettersen, R. I., Gadoury, D. M., and Gislerød, H. R. 2010. Specific light emitting diodes can suppress sporulation of Podosphaera pannosa on greenhouse roses. Plant Dis. 94:1105-1110.

49. Wang, H., Jiang, Y. P., Yu, H. J., Xia, X. J., Shi, K., Zhou, Y. H., and Yu, J. Q. 2010. Light quality affects incidence of powdery mildew, expression of defence related genes and associated metabolism in cucumber plants. Eur. J. Plant Pathol. 127:125-135.

50. Willocquet, L., Colombet, D., Rougier, M., Fargues, J., and Clerjeau, M. 1996. Effects of radiation, especially ultraviolet B, on conidial germination and mycelial growth of grape powdery mildew. Eur. J. Plant Pathol. 102:441-449.

51. Wyenandt, C. A., Maxwell, N., and Ward, D. L. 2008. Fungicide programs affect 'practical' resistance development in cucurbit powdery mildew of pumpkin. HortScience 43:1838-1845.

52. Zitter, T. A. 1996. Compendium of Cucurbit Diseases. American Phytopathological Society, St. Paul, MN. 